\title{
In vivo Analgesic and CNS Depressant Activities of Antioxidative Stem Bark Fraction of Morus alba L.
}

\section{Muhammad Ali Khan ${ }^{1}$, Aziz Abdur Rahman², Laizuman Nahar², Md Badrul Islam ${ }^{3}$ and A.H.M. Khurshid Alam²}

\author{
${ }^{1}$ Department of Pharmacy, Bangabandhu Sheikh Mujibur Rahman Science and Technology University, \\ Gopalgonj, Bangladesh \\ ${ }^{2}$ Department of Pharmacy, University of Rajshahi, Rajshahi-6205, Bangladesh \\ ${ }^{3}$ Senior Scientific Officer, BCSIR, Rajshahi-6205, Bangladesh
}

Received: May 04, 2014; Accepted: June 02, 2014; Published (web): July 06, 2014

The present study is the continuation of our previous finding ${ }^{1}$ where we reported comparative antioxidant properties as well as phenolic contents of methanolic extracts from leaf, fruit, root and stem barks of Morus alba L. (Moraceae, white mulberry) and concluded that stem bark was the potent source of antioxidants. According to folk research, M. alba that has a long history of medicinal use in Chinese as well as Indian herbal medicine is known to show antioxidant, analgesic and CNS depressant activities. $^{2,3}$ However, there is no clear finding that shows the correlation among these activities. Hence, our present research was conducted to evaluate the rationale of folkloric reputation of $M$. alba by studying in vivo analgesic and CNS depression activity of the antioxidative fraction in mice.

Stem barks of $M$. alba were collected from the botanical garden of Rajshahi University, Rajshahi, Bangladesh and were identified by a taxonomist at the Department of Botany, University of Rajshahi (Voucher No. 50). The dried grinded stem powder $(1 \mathrm{~kg})$ was extracted with methanol using cold extraction process to get brownish red colored extract (MEMA, $39 \mathrm{~g}$ ). For biological activity, Swiss albino mice, aged 4 weeks and weighing between 40-45 g of both sexes, were purchased from ICDDR,B

Correspondence to: A.H.M. Khurshid Alam Tel: +880721711110 (office); Fax: +880721750064;

E-mail: khurshid.jaist@gmail.com

Dhaka Univ. J. Pharm. Sci. 13(2): 225-227, 2014 (December)
(International Centre for Diarrhoeal Disease Research in Bangladesh), Dhaka. The animals (for each test) were divided into four groups of five animals each: Group I (control), Group II (standard), and Group III and Group IV (experimental groups). Protocol used in this study for the use of mice was approved by the Institutional Animal, Medical Ethics, Biosafety and Biosecurity Committee (225/320-IAMEBBC/ IBSc), Institute of Biological Sciences, Rajshahi University.

Acetic acid-induced writhing method described by Hasan et $a l^{4}$ and formalin-induced pain test reported by Sharma et al..$^{5}$ were used to determine the analgesic activity of the extract at a dose of 100 and $200 \mathrm{mg} / \mathrm{kg}$ bw. CNS-depressant activity was measured by open field ${ }^{6}$ and hole cross ${ }^{7}$ test at a dose of 250 and $500 \mathrm{mg} / \mathrm{kg}$ bw.

In acetic-acid induced writhing test it was found the MEMA at 100 and $200 \mathrm{mg} / \mathrm{kg}$ bw showed writhing inhibition of $56.96 \%$ and $63.91 \%$, respectively whereas standard indomethacin showed analgesic activity with writhing inhibition of $58.86 \%$ when compared with the control group whereas in formalin-induced pain test the MEMA showed dosedependent decrease in licking time. Analgesic activity at $100 \mathrm{mg} / \mathrm{kg}$ was 72.89 whereas at 200 $\mathrm{mg} / \mathrm{kg}, 43.45$ in the early phase when compared with diazepam (47.18). In the late phase, the MEMA showed significant score of pain (47.11 and 39.85 at 100 and $200 \mathrm{mg} / \mathrm{kg}$ bw, respectively) as well as percentage of inhibition of pain (52.89 and 60.15 at 
100 and $200 \mathrm{mg} / \mathrm{kg}$ bw, respectively) when compared with standard (47.46 and 52.54, respectively).

In open field test the extract showed dose dependent reduction of behavioral activities which were statistically significant. A noticeable result was found at $120 \mathrm{~min}$ after the administration of MEMA with a significant decrease in number of movement at a dose of 250 and $500 \mathrm{mg} / \mathrm{kg}(22.6 \pm 4.83$ and $14.8 \pm$ 2.95 , respectively, as compared to $118.0 \pm 1.58$ in the control group and $9.6 \pm 1.14$ in the standard group). The hole cross test showed dose dependent reduction in the locomotor activity. At higher dose, the reduction of locomotor activity was similar to that of standard diazepam and the depressant effect on CNS was found to be statistically significant.

Intra-peritoneal administration of acetic acid causes localized inflammation in mice due to biosynthesis of prostaglandin and leukotriens through cyclooxygenase and lipooxygenase pathway. ${ }^{8}$ The released prostaglandins, mainly $\mathrm{PGI}_{2}$ and to lesser extent $\mathrm{PGE}_{2}$, were responsible for pain sensation. So, the significant analgesic activity of the methanolic extract of $M$. alba was thought to be due to its possible interference in the biosynthesis of prostaglandin and possible other mediators. The pain in the early phase of formalin-induced pain test was due to the direct stimulation of the sensory nerve fibers by formalin, while the pain in the late phase was due to inflammatory mediators, like histamine, prostaglandins, serotonin and bradykinins. ${ }^{9}$ In our present study, the MEMA showed dose-dependent decrease in licking time suggesting MEMA blocked the stimulation of sensory nerve fiber necessary to produce pain.

Satisfactory results from CNS-depressant activity tests revealed that the MEMA display a behavioral profile that is consistent with an anxiolytic and CNS-depressant action. It has been reported that flavonoids bind with high affinity to the benzodiazepine side of the $\mathrm{GABA}_{\mathrm{A}}$ receptor, ${ }^{10}$ hence, it is possible that the presence of several polyphenols ${ }^{1}$ in the extract, could account for its effect on CNS. The MEMA significantly reduced the locomotor activity as shown by the result of the open field and hole cross tests. In both of the test, MEMA showed dose dependent reduction of locomotor activity which was comparable to the standard. It has been reported that increased locomotor activity considered as an increase in alertness and decreased locomotor activity was associated with sedative effect. ${ }^{11}$ Our findings indicated that MEMA showed CNSdepressant activity by decreasing locomotor activity. Therefore it is possible that the methanolic extract of $M$. alba may act by potentiating the inhibition of $\mathrm{GABA}_{B}$ receptor in the CNS via membrane hyper polarization which leads to a decrease in the firing rate of critical neurons in the brain or may be due to direct inhibition of $\mathrm{GABA}_{\mathrm{B}}$ receptor by the extract.

On the basis of our results obtained from the present study, it can be concluded that the methanol extract of the stem bark of Morus alba possesses remarkable CNS-depressant activity and thereby supports to the traditional use of the stem bark of this plant in mental disorders. Present work was a preliminary effort which will require further detailed investigation including characterization of active compounds and requires preformulation studies for development of a potential dosage form.

\section{REFERENCES}

1. Khan, M.A., Rahman, A.A., Islam, S., Khandokhar, P., Parvin, S., Islam, M.B., Hossain, M., Rashid, M., Sadik, G., Nasrin, S., Mollah, M.N.H. and Alam, A.H.M.K. 2013. A comparative study on the antioxidant activity of methanolic extracts from different parts of Morus alba L. (Moraceae). BMC Research Notes 6, 24 (doi:10.1186/1756-0500-6-24).

2. Abbasi, A.M., Khan, M.A., Ahmad, M., Zafar, M., Khan, H., Muhammad, N. and Sultana, S. 2009. Medicinal plants used for the treatment of jaundice and hepatitis based on socioeconomic documentation. Afr. J. Biotec. 8, 1643-1650.

3. Yang, X., Yang, L. and Zheng, H. 2010. Hypolipidemic and antioxidant effects of mulberry (Morus alba) fruit in hyperlipidaemia rats. Food Chem. Toxicol. 48, 2374-2379.

4. Hasan, S.M.R., Hossain, M.M., Akter, R., Jamila, M. and Mazumder, M.E.H. 2010. Analgesic activity of the different fractions of the aerial parts of Commelina benghalensis Linn. Int. J. Pharmacol. 6, 63-67.

5. Sharma, A., Bhatial, S., Kharyaz, M.D., Gajbhiye, V., Ganesh, N., Namdeo, A.G. and Mahadik, K.R. 2010. Antiinflammatory and analgesic activity of different fractions of Boswellia serrata. Int. J. Phytomed. 2, 94-99. 
6. Gupta, B.D., Dandiya, P.C. and Gupta, M.L. 1971. A psychopharmacological analysis of behavior in rat. Jpn. J. Pharmacol. 21, 293-298.

7. Takagi, K., Watanabe, M. and Saito, H. 1971. Studies on the spontaneous movement of animals by the hole cross test: Effect of 2-dimethylaminoethane acylates on the central nervous system. Jpn. J. Pharmacol. 21, 797-810.

8. Ricciotti, E. and FitzGerald, G.A. 2011. Prostaglandins and Inflammation. Arterioscler. Thromb. Vasc. Biol. 31, 9861000 .

9. Dharmasiri, J.R., Jayakody, A.C., Galhena, G., Liyanage, S.S.P. and Ratnasooriya, W.D. 2003. Antiinflammatory and analgesic activities of mature fresh leaves of Vitex negundo. J. Ethnopharmacol. 87, 199-206.
10. Kahnberg, P., Lager, E., Rosenberg, C. and Schougaard, C.L. 2002. Refinement and evaluation of a pharmacophore model for flavones derivatives binding to the benzodiazepine site of the $\mathrm{GABA}_{\mathrm{A}}$ receptor. J. Med. Chem. 45, 4188-4201.

11. Verma, A., Goutam, K.J., Saikat, S., Raja, C., Sandeep, S. and Ashutosh, M. 2010. Pharmacological evaluation of Saraca indica leaves for central nervous system depressant activity in mice. J. Pharma. Sci. Res. 2, 338-343. 